\title{
Trend Analysis of Malaria Prevalence in Bati District, Northeastern Ethiopia (From 2015 to 2020): A Retrospective Study
}

chala daba ( $\square$ chaladaba293@gmail.com )

Wollo University

Edosa Kebede

Ambo University

Amanuel Atamo

Wollo University

\section{Research}

Keywords: Bati, Malaria, P. vivax, P. falciparum, Ethiopia

Posted Date: April 27th, 2021

DOI: https://doi.org/10.21203/rs.3.rs-447896/v1

License: (c) (i) This work is licensed under a Creative Commons Attribution 4.0 International License.

Read Full License 


\section{Abstract}

Background: Malaria is the leading cause of morbidity and mortality in developing country including Ethiopia. Ethiopia is one of on ways to minimize the incidence of malaria by $40 \%$ as per its 2020 malaria reduction strategy since 2016 . Thus, this study aimed to analyze six-year trend analysis of malaria prevalence in Bati district, Northeastern Ethiopia.

Methods: Institutional based retrospective study was conducted to determine six-year trend analysis of malaria prevalence in Bati district. All malaria cases reported from 2015 to 2020 were carefully reviewed by trained laboratory technologist from the laboratory record books of Bati hospital and health center.

Results: A total of 84,269 and 22,185 of malaria suspected patients were requested for blood films and Rapid diagnostic test (RDT) respectively. Of this, 12,032 (11.3\%) malaria cases were microscopically confirmed. Plasmodium falciparum were the most dominant parasites detected, which accounted $57.6 \%$. Malaria has been reported from all age groups; however, age distribution showed that the majority of cases were adults' age 15 years (57.2\%). Even though there was fluctuation of malaria prevalence in the study area, the highest peak of malaria cases was reported during summer season which accounted $47.2 \%$.

Conclusion: Malaria is still a major public health problem in Bati district and the overall trend of total confirmed malaria cases were decreased in the past six years (2015-2020) with exception slightly increased cases from 2015 to 2016 . Therefore, government, all healthcare workers and community should strengthen and scale up malaria prevention and control strategies in the study area

\section{Introduction}

Malaria has been characterized as a major public health problem and posse a high mortality and morbidity globally[1, 2]. It is caused by Plasmodium parasites[3]. In 2018, there were an estimated 228 million of malaria cases and 405000 deaths. Of these death, 67\% (272 000) were under five children globally. This is true that the burden of malaria is more overwhelming in children and pregnant women because of their weaker immune system. According to world health organization around 213000 (93\%) of malaria cases and 380000 deaths were reported in Africa followed by South-East Asia Region with $3.4 \%[4]$. In addition to this, $30 \%$ of the overall disability adjusted life years are lost, making it a significant impediment to social and economic development[5].

Among plasmodium parasites, Plasmodium falciparum and Plasmodium vivax are the most widely distributed and pose the greatest public health threat particularly developing country[6]. In Ethiopia, an estimated 1.2 million cases are reported in 2018 [5] and 2,927,266 new malaria cases and 4782 deaths are reported in 2016. Malaria is the foremost cause of morbidity and mortality in Ethiopia, accounting for over five million cases and thousands of deaths annually[7]. This is mainly due to $75 \%$ of the country is malarias area with about $68 \%$ of the total population living are live under risk of contracting malaria 
disease[8-10]. Moreover, the topography and climate condition of the Ethiopia are more variable and unstable which make favorable condition for malaria transmission [11].

To reduce the challenge of this malarias problem, Ethiopia has been applying malaria prevention and control strategies such as early diagnosis and prompt treatment, selective vector control by indoor residual spraying (IRS), insecticide-treated mosquito nets (ITNs) and environmental management[12, 13]. Furthermore, Ethiopia has just targeted malaria elimination nationwide at the end of 2030 aligned with the World Health Organization (WHO) Global Technical Strategy (GTS) through increasing the existing malaria prevention and control activities[14]. Now a day, Ethiopia is on a way to achieve the 2020 milestone by reducing the incidence of malaria by $40 \%[15]$. Analyzing the seasonal trends and prevalence of malaria from health institution is the easiest and effective methods and also it is input for expanding the prevention and control strategy as well as for designing new policies for appropriate intervention that could assist in the elimination of malaria in 2030. Accordingly, Bati district was one of the hot areas where malaria epidemic control interventions were undertaken and there is a limitation of malaria trends data at Bati district. Thus, this study aimed to assess the trend of malaria prevalence in Bati district from 2015 to 2020.

\section{Methods}

\section{Study area}

The study was conducted in Bati district which is special Oromia zone of Amhara national regional state, Northeastern Ethiopia. The data was collected from Bati hospital and health center. It is located at $11^{\circ} 11^{\prime} \mathrm{N}, 40^{\circ} 11^{\prime} \mathrm{E}$ is $1502 \mathrm{~m}$ above sea level. The mean annual rainfall is $155.1 \mathrm{~mm}$, and the maximum and minimum annual mean temperature of the town is $28^{\circ} \mathrm{C}$ and $8^{\circ} \mathrm{C}$, respectively. The district is under malaria's area.

\section{Study design}

Institutional based retrospective study design was employed to determine six-year $(2015$ - 2020) trend analysis of malaria prevalence in Bati district from October to December 2020.

\section{Data collection}

Six-year malaria cases data were collected from Bati Hospital and health center laboratory log books from January 2015 to December 2020. Total malaria cases diagnosed in months and years, total number of blood film examined, species type such as $P$. falciparum, $P$. vivax and age were collected by trained Medical laboratory technologists. In Bati hospital and health center, microscopy is used as a golden standard to confirm the presence of Plasmodium parasite and species identification.

The study hospital and health center strictly follow the standard operating procedures (SOPs) in all phases of the quality control. All hospitals and health centers follow a standard operating procedure (SOP) in Ethiopia throughout the country for capillary blood sample collection, smear preparation, 
staining and blood film examination for malaria parasite detection [16]. In these study areas, thick blood films were taken as positive if one or more malaria parasites have been observed; and, negative if no parasites were seen after examining 1000 white blood cells. Similarly, thin smears were considered positive for malaria if one or more malarial parasites were seen; and, negative if no asexual form of Plasmodium was observed in 200 high-power fields [17].

\section{Data analysis}

Data were entered into excel and descriptive statistics were used to analyze microscopically confirmed malaria cases with month and year. Malaria prevalence was computed by dividing the number of people who showed infection with Plasmodium species to the total number of people examined from the study population. Graphs and table were used to depict the overall trend of malaria prevalence and malaria species distribution and season.

\section{Results}

\section{Trend of malaria prevalence in Bati district from 2015 to 2020}

Within the previous six years (2015-2020), a total of 106,454 malaria-suspected patients were diagnosed at both Bati hospital and health center. Out of these, 84,269 and 22,185 of malaria suspected patients were requested for blood films and RDT respectively. From total this infected, 12,032 (99.6\%) of malaria cases were confirmed by microscope with the average annual of 2,005. The number of malaria cases was reported though out the year with different amount. The results of this study showed that the number of confirmed malaria cases was steady increased from 2015 to 2016 . However, slightly decreasing trend in number of confirmed malaria cases was observed from 2016 to2019 and steady increased from 2019 to 2020. In fact, the prevalence of malaria was fluctuating during the six years of study with minimum ( $\mathrm{n}$ $=674)$ and maximum $(n=3,616)$ of annual malaria confirmed cases was reported by 2019 and 2016 years respectively. Thus, the total malaria prevalence over the six years in the Bati district was $11.3 \%$.

\section{Prevalence of malaria parasites with respect to ageat Bati district}

Of diagnosed Plasmodium species, $P$. falciparum was the predominant species that accounted $57.6 \%$. On other hand, overall, the prevalence of $P$. falciparum in the study area was $6.5 \%$, meanwhile $P$. vivax was $(4.8 \%)$; this indicates that $P$. falciparum was dominant parasitic species in the study area. In the study area, the malaria cases were observed in all age groups. And the most affected age group was $>15$ years old which accounted $57.2 \%(6,879)$ followed by $5-14$ age group $24.5 \%(2,953)$ while the least affected age group was under five age $18.3 \% \%(2,200)$. Similarly, comparable percentage of both $P$. falciparum and $P$. vivax were reported from all groups in each age category (Fig. 3).

\section{Seasonal and monthly variation of malaria cases in Bati district}


Even though the prevalence of malaria has fluctuated through year, malaria was reported in all months and seasons. In this study, the maximum number of confirmed malaria cases was reported during summer (June, July and August) and the minimum was reported during autumn. At species level, the highest both $P$. falciparum and $P$. vivax were reported during summer while the smallest was autumn (Fig. 4).

\section{Malaria case distribution at Bati district from 2015 to 2020}

The present study showed that malaria cases distributed throughout the study year. The highest malaria cases were reported during 2016 which was plasmodium falciparum.

Table 1

Malaria case distribution at Bati district from 2015 to 2020

\begin{tabular}{|llllll|}
\hline Years & $\begin{array}{l}\text { Total numbers blood } \\
\text { film examined }\end{array}$ & $\begin{array}{l}\text { Total numbers of RDT } \\
\text { examined }\end{array}$ & & $\begin{array}{l}\text { Total } \\
\text { confirmed } \\
\text { cases }\end{array}$ & \multicolumn{2}{l|}{$\begin{array}{l}\text { Plasmodium } \\
\text { species }\end{array}$} \\
\cline { 5 - 7 } & & 2662 & & $\begin{array}{l}\text { p. } \\
\text { falciparum }\end{array}$ & $\begin{array}{l}\text { p. } \\
\text { vivax }\end{array}$ \\
\hline 2015 & 12338 & 3883 & 2220 & 1287 & 933 \\
\hline 2016 & 18427 & 4720 & 3616 & 2042 & 1574 \\
\hline 2017 & 17800 & 4923 & 3023 & 1379 & 1644 \\
\hline 2018 & 18324 & 34 & 1588 & 855 & 733 \\
\hline 2019 & 13264 & 5963 & 674 & 532 & 142 \\
\hline 2020 & 4116 & 22185 & 911 & 840 & 71 \\
\hline Total & $\mathbf{8 4 2 6 9}$ & & 12032 & 6935 & 5097 \\
\hline
\end{tabular}

\section{Discussion}

According to this study, the total prevalence of malaria cases over six-years was $11.3 \%$. This result was noticeably lower than $48 \%, 36.1 \%, 33.8 \%, 21.8 \%$ and $17 \%$ reported from the nearby localities of Woreta town, northwest Ethiopia ; Addi Arkay health center, northwest Ethiopia; and Abeshge, South-central Ethiopia; Gondar, northwest Ethiopia; Metema hospital northwest Ethiopia, respectively [18-22]. On the other hand, it was higher than the studies conducted in Ataye, North Shoa, Ethiopia (8.4\%), Bahirdar city (5\%) and kombolcha town $(7.5 \%)[16,23,24]$.The differences might be due to time variations of the studies, the difference of malaria prevention and control implementation activities, variations in geographical locations and difference in insecticide application in the areas.

According to this study, the number of confirmed malaria cases was steady increased from 2015 to 2016 which indicates that the area needs attention to intensify the existing interventions to enhance malaria elimination efforts. However, slightly decreasing trend in number of confirmed malaria cases was 
observed from 2016 to2019. This reduction of malaria cases over three year was due to the Bati health district was consistently implemented malaria prevention and control including distribute Insecticide Treated Net (ITN), create health awareness about malaria prevention and control to the community. This reduction is also due to effective malaria control and prevention strategies which are being implemented by Federal Ministry of Health in the whole malaria areas by giving emphasis to reduce malaria cases to zero.

Regarding to distribution of plasmodium species in the study area, Plasmodium falciparum was the dominant species which accounted $57.6 \%$ followed by $P$. viva $42.4 \%$. This result was similar with the retrospective studies conducted in Raya Azebo which accounted Plasmodium falciparum( $56.9 \%)$ and $P$. viva43.1\% [23] and around Gilgel Gibe Hydroelectric Dam (GGHD), which accounts Plasmodium falciparum (54.6\%) and Plasmodium vivax(41.6\%)[24]. As compare to the studies, this finding is agreement with malaria species distribution in several parts of Ethiopia such as Kola Diba, North Gondar; Raya Azebo Northern Ethiopia; Butajira, Southern Ethiopia; Jimma, Southwest Ethiopia [2, 23, 25, 26]. On other hand, the prevalence of $p$. falciparum was slightly less than a result reported from a retrospective study reported in Kola Diba health center (75\%)[26]. This is mainly due to the implementation of malaria prevention and control activities which might differ from one area to another showing that the interventions in our study area might have been stronger.

The numbers of confirmed malaria cases were varied from season to season and also year to year. In fact, the prevalence and magnitude of malaria transmission are mainly determined by environmental, climatic, seasonal factors and behavioral factors. In this study, the highest malaria cases were reported during summer season (47.2\%). This result was in agreement with the retrospective studies conducted in Kombolcha, Ethiopia; Ataye Northshoa; Northwest Gondar, Ethiopia[16, 20, 27]. This might be due to the similarity of climate condition and altitude difference. This is also true as explained by federal democratic republic of Ethiopia ministry of health national strategic plan for malaria prevention there two peak malaria transmission seasons are from September to December and following the rainy season from June to September. However, in this study, malaria cases were high at summer season. This is may be due to relapsing behavior of malaria parasite and irregular rain-full in the area[9].

According to this study, malaria was detected in all age groups. In current study, the highest prevalence of malaria was observed among $\geq 15$ age groups (57.2\%) followed by 5 to 15 age groups (24.5\%) and under five children (18.3\%). This results was similar to the findings of studies conducted in Raya Azebo; Addi Arkay health center; Ataye Northshoa; and Abeshge, South-central Ethiopia; Northwest Gondar[20-22, 27, 28].This might be due to the fact that productive age groups often engaged in farm activities in the fields.

\section{Conclusion}

Plasmodium falciparum were dominant and followed by Plasmodium vivax. The overall trends of total confirmed malaria cases were decreased in the past 6 years (2015-2020) with exception slightly increased in cases from 2015 to 2016. In general, malaria is a major public health problem in the Bati 
district. Therefore, government, all healthcare works and communities should strengthen and scale up malaria prevention and control strategies in the study area.

\section{Abbreviations}

IRS: Indoor Residual Spray; BF: Blood Film; ITNs: Insecticide-Treated Nets; RDT: Rapid Diagnostic Tests; SOPs: Standard Operating Procedures; WHO: World Health Organization

\section{Declarations}

\section{Ethics approval and consent to participate}

Ethical clearance was obtained from the ethical review committee of Wollo University. After discussing the purpose and method of the study, verbal consent was obtained from the heads of health institutions before the data extraction.

\section{Consent for publication}

Not applicable

\section{Availability of data and materials}

The datasets used and/or analyzed during the current study are available in the hands of the corresponding authors.

\section{Competing interests}

The authors declare that they have no competing interests

\section{Funding}

No fund was received for this research

\section{Authors' contributions}

$\mathrm{CD}$, EK and $\mathrm{AA}$ involved in proposal writing, methodology development and review the document and analyze the data and manuscript preparation

\section{Acknowledgements}

We would like to acknowledge Wollo University, College of Medicine and Health Science to write the support letter and Bati health center and Hospital manager for their cooperation during data extraction

\section{References}


1. Yewhalaw D, Legesse W, Van Bortel W, Gebre-Selassie S, Kloos H, Duchateau L, et al. Malaria and water resource development: The case of Gilgel-Gibe hydroelectric dam in Ethiopia. Malar J. 2009;8(1):1-10.

2. Tesfaye S, Belyhun Y, Teklu T, Mengesha T, Petros B. Malaria prevalence pattern observed in the highland fringe of Butajira, Southern Ethiopia: A longitudinal study from parasitological and entomological survey. Malar J. 2011;10:1-9.

3. Martens P, Hall L. Malaria on the move: Human population movement and malaria transmission. Emerg Infect Dis. 2000;6(2):103-9.

4. WHO. World malaria report 2019. 2019.

5. CDC. U . S . Presedent malaria intitiative ethiopia malaria Operational Plan FY 2020. 2020.

6. UNICEF/WHO. Achieving the malaria MDG target: reversing the incidence of malaria 2000-2015. WHO Glob Malar Program

7. Girum T, Shumbej T, Shewangizaw M. Burden of malaria in Ethiopia, 2000-2016: Findings from the Global Health Estimates 2016. Trop Dis Travel Med Vaccines. 2019;5(1):5-11.

8. CDC U. President 'S Malaria Initiative Malaria Operational Plan ( Mop ) Ethiopia Fy2012. Malar J. 2009;2009, 8:29.

9. FMOH. National Strategic Plan for Malaria Prevention Control and Elimination in Ethiopia 2011-2015. 2010;2015(August 2010):76.

10. Woyessa A, Deressa W, Ali A, Lindtjørn B. Prevalence of malaria infection in Butajira area, southcentral Ethiopia. Malar J. 2012;11(1):84.

11. Petros B, Geshere G. Trend of Malaria Prevalence in Ilu Galan, Bako Tibe, and Danno Districts of West Shoa Zone, OromiyaRegion, Ethiopia. 2014;(May).

12. Gari T, Lindtjørn B. Reshaping the vector control strategy for malaria elimination in Ethiopia in the context of current evidence and new tools: Opportunities and challenges 11 Medical and Health Sciences 1108 Medical Microbiology 11 Medical and Health Sciences 1117 Public He. Malar J [Internet]. 2018;17(1):1-8. doi.org/10.1186/s12936-018-2607-8

13. Taffese HS, Hemming-Schroeder E, Koepfli C, Tesfaye G, Lee MC, Kazura J, et al. Malaria epidemiology and interventions in Ethiopia from 2001 to 2016. Infect Dis Poverty. 2018;7(1):1-9.

14. FDRE. Federal Democratic Republic of Ethiopia Ministry of Health. National Malaria Elimination Roadmap. Addis Ababa. 2016;6(1):1-32.

15. WHO. World malaria report 2018. Geneva: World Health Organization; 2018. https://www.who.int/malaria/publications/ world-malaria-report-2018/en/. 2018.

16. Feleke DG, Gebretsadik D, Gebreweld A. Analysis of the trend of malaria prevalence in Ataye, North Shoa, Ethiopia between 2013 and 2017. Malar J [Internet]. 2018;17(1):1-6. doi.org/10.1186/s12936018-2474-3

17. Moges B, Amare B, Belyhun Y, Tekeste Z, Gizachew M, Workineh M, et al. Comparison of CareStart HRP2/pLDH COMBO rapid malaria test with light microscopy in north-west Ethiopia. Malar J. 
2012;11:1-6.

18. Alelign A, Tekeste Z, Petros B. Prevalence of malaria in Woreta town, Amhara region, Northwest Ethiopia over eight years. BMC Public Health. 2018;18(1):1-6.

19. Ferede G, Worku A, Getaneh A, Ahmed A, Haile T, Abdu Y, et al. Prevalence of malaria from blood smears examination: A seven-year retrospective study from Metema Hospital, Northwest Ethiopia. Malar Res Treat. 2013;2013:0-2.

20. Addisu A, Tegegne Y, Mihiret Y, Setegn A, Zeleke AJ. A 7-Year Trend of Malaria at Primary Health Facilities in Northwest Ethiopia. J Parasitol Res. 2020;2020.

21. Tesfa H, Bayih AG, Zeleke AJ. A 17-year trend analysis of malaria at Adi Arkay, north Gondar zone, Northwest Ethiopia. Malar J. 2018;17(1):1-6. doi.org/10.1186/s12936-018-2310-9

22. Yimer F, Animut A, Erko B, Mamo H. Past five-year trend, current prevalence and household knowledge, attitude and practice of malaria in Abeshge, south-central Ethiopia. Malar J. 2015;14(1):1-11, doi.org/10.1186/s12936-015-0749-5

23. Gebretsadik D, Feleke DG, Fiseha M. Eight-year trend analysis of malaria prevalence in Kombolcha, South Wollo, north-central Ethiopia: A retrospective study. Parasites and Vectors. 2018;11(1):1-6.

24. Yimer M, Hailu T, Mulu W, Abera B, Ayalew W. A 5 year trend analysis of malaria prevalence with in the catchment areas of Felegehiwot referral Hospital, Bahir Dar city, northwest-Ethiopia: A retrospective study. BMC Res Notes. 2017;10(1):4-7.

25. Tesfay K, Yohannes M, Bayisa S. Trend analysis of malaria prevalence in Raya Azebo district, Northern Ethiopia: A retrospective study. BMC Res Notes [Internet]. 2018;11(1):1-5. doi.org/10.1186/s13104-018-4003-4

26. Sena LD, Deressa WA, Ali AA. Analysis of trend of malaria prevalence in south-west Ethiopia: A retrospective comparative study. Malar J. 2014;13(1):1-9.

27. Alemu A, Tsegaye W, Golassa L, Abebe G. Urban malaria and associated risk factors in Jimma town, south-west Ethiopia. Malar J. 2011;10:1-10.

28. Abebe, alemu; dagnachew, muluye;mikrie, mihret; meaza, adugna; melkamu gebeyaw. Ten year trend analysis of malaria prevalence in Kola Diba, North Gondar, Northwest Ethiopia. parasite and vectors. 2012;9(6):277-81.

29. Hawaria D, Getachew H, Zhong G, Demissew A, Habitamu K, Raya B, et al. Ten years malaria trend at Arjo-Didessa sugar development site and its vicinity, Southwest Ethiopia: A retrospective study. Malar J [Internet]. 2019;18(1):1-11.doi.org/10.1186/s12936-019-2777-z

\section{Figures}




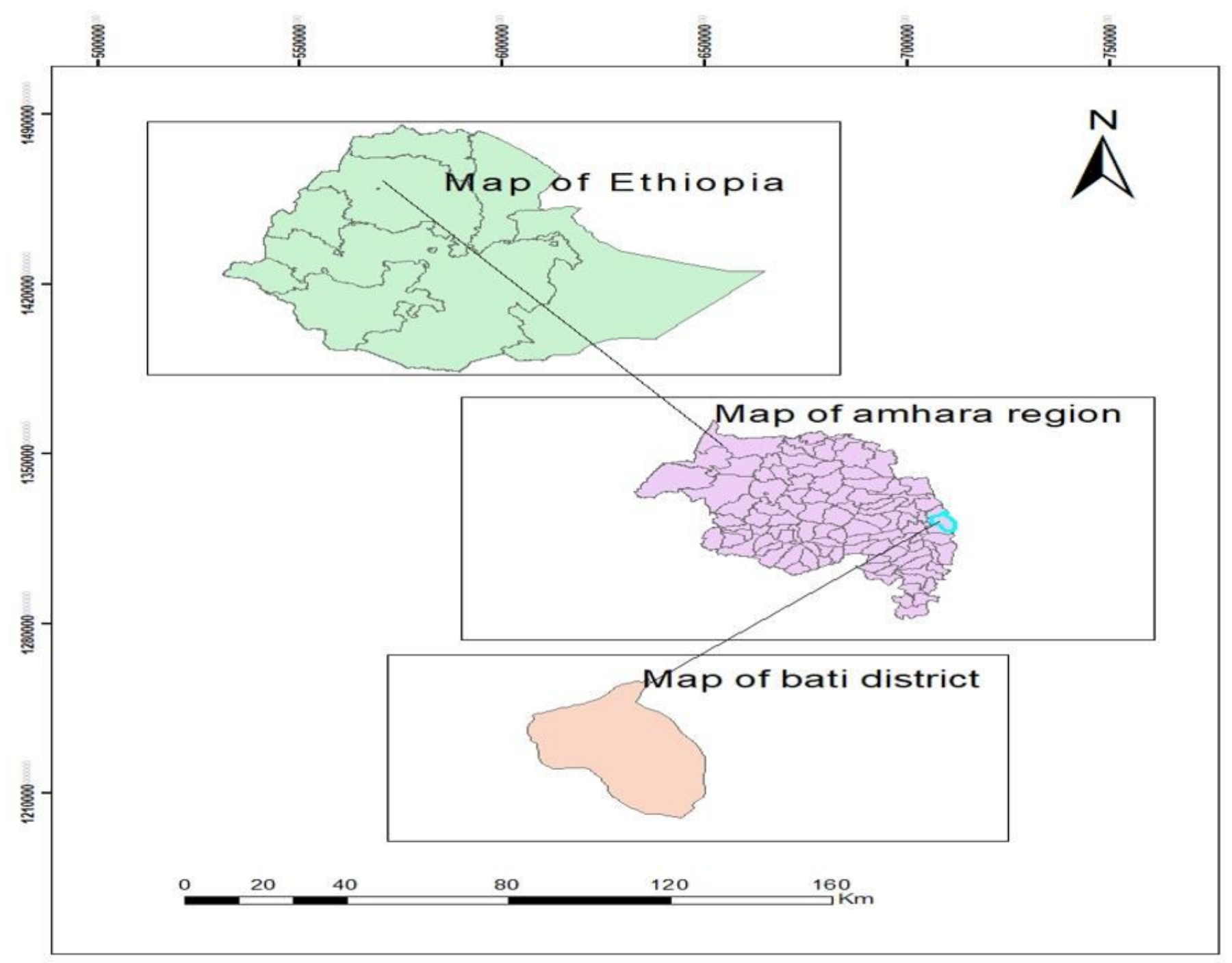

\section{Figure 1}

Map of the study area Note: The designations employed and the presentation of the material on this map do not imply the expression of any opinion whatsoever on the part of Research Square concerning the legal status of any country, territory, city or area or of its authorities, or concerning the delimitation of its frontiers or boundaries. This map has been provided by the authors. 


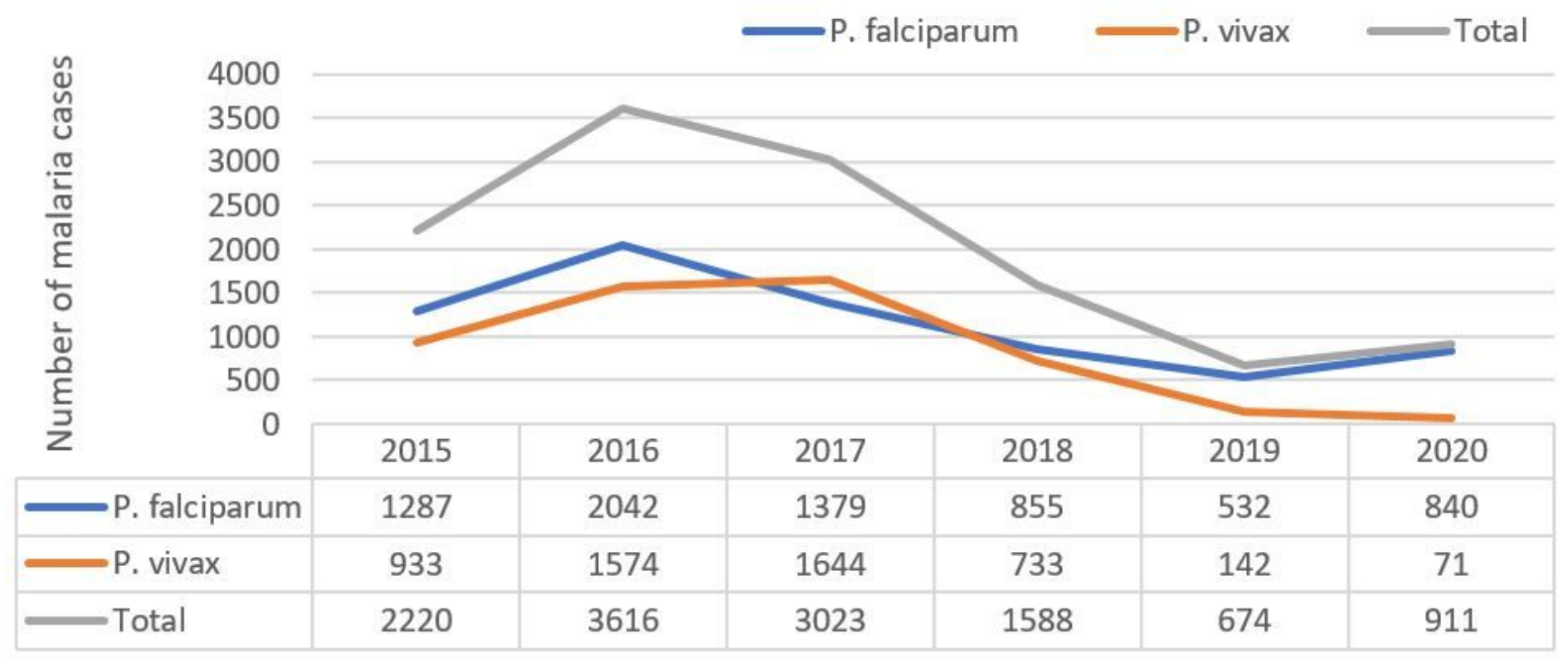

Figure 2

Anualy prevalence of malaria cases at Bati district, Ethiopia from 2015 to 2020

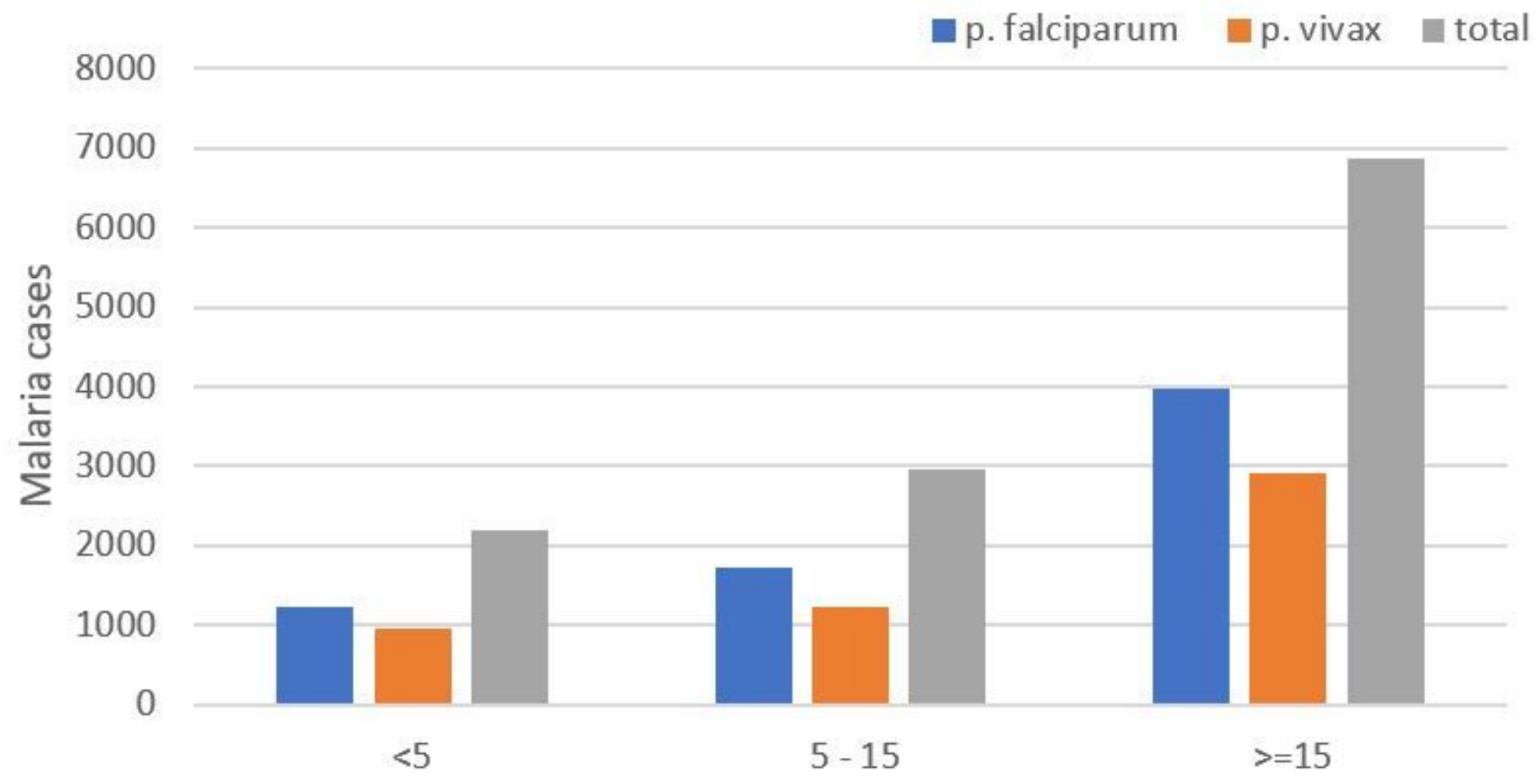

Figure 3

Six year trend analysis of malaria species by age at Bati district from 2015 to 2020 


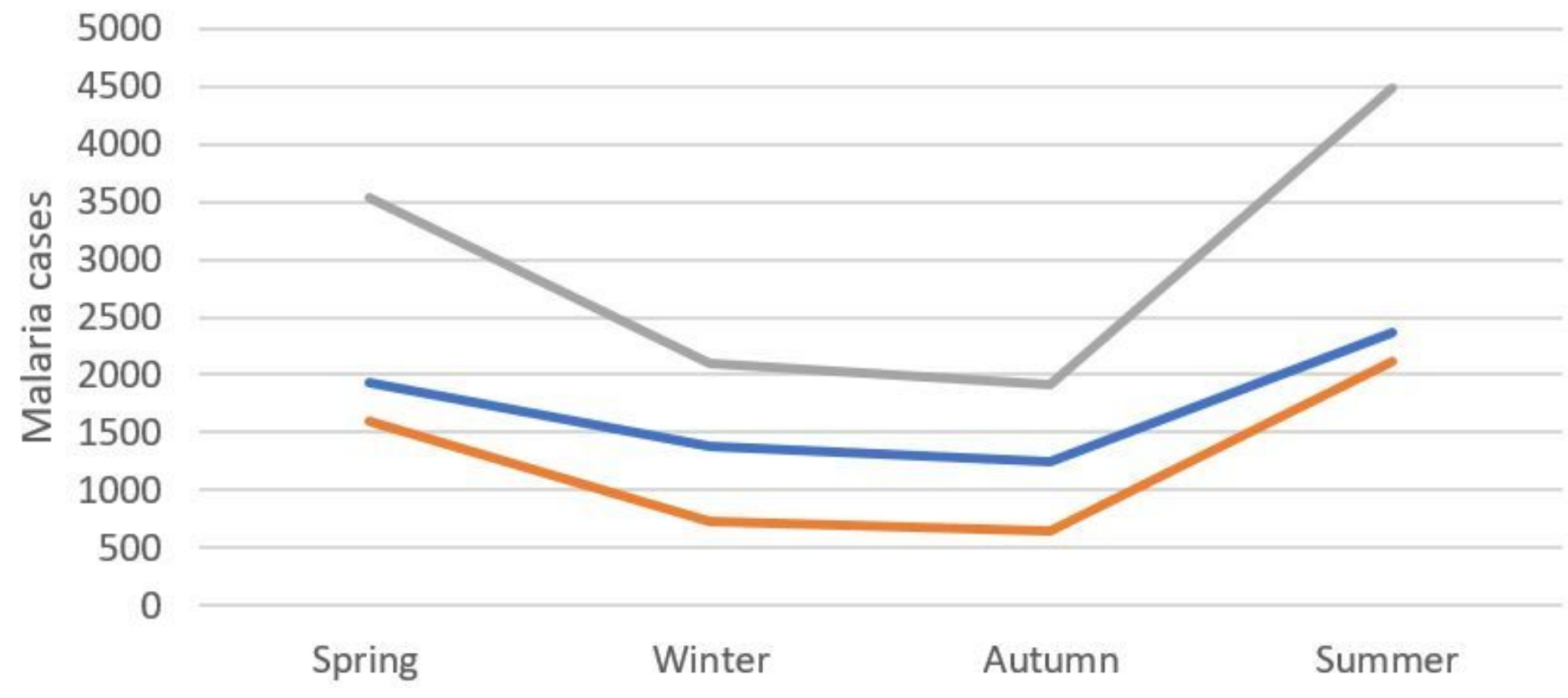

Figure 4

Six year trend analysis of plasmodium apecies by season at Bati district from 2015 to 2020

\section{घf $\mathbf{p v}$}

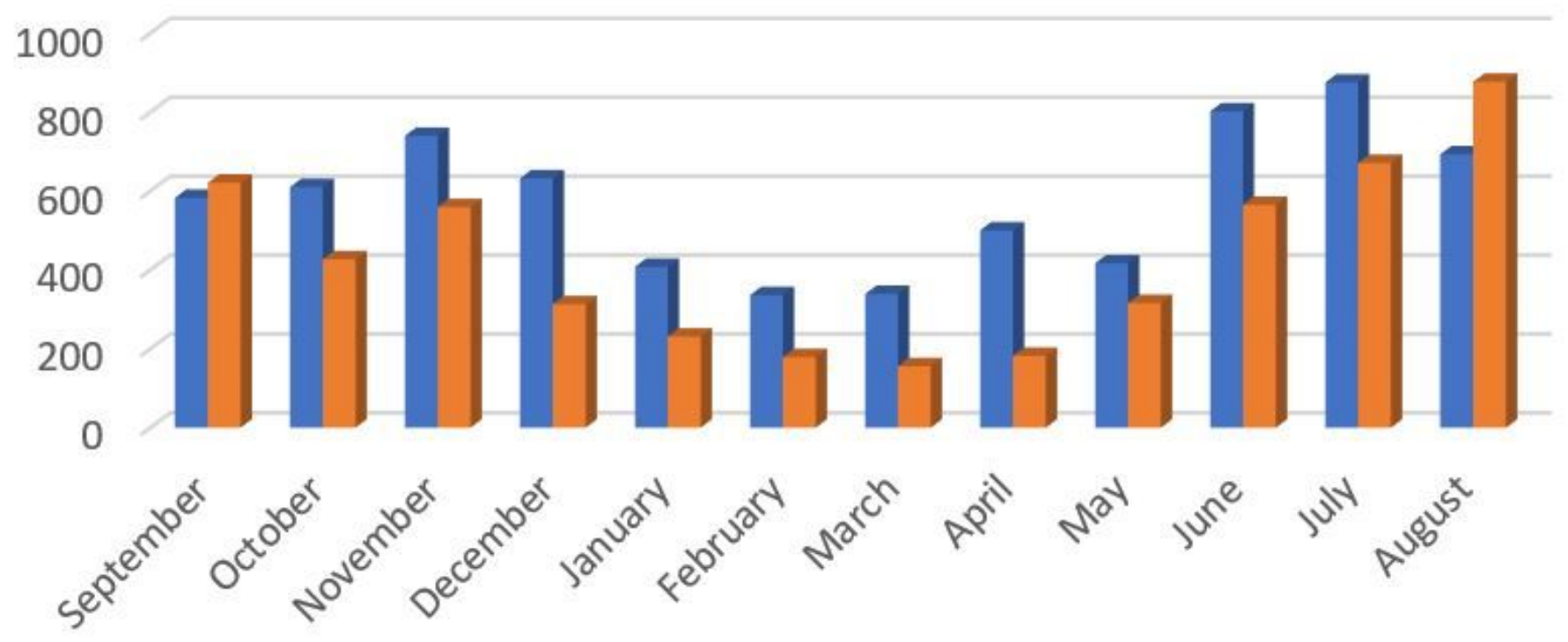

\section{Figure 5}

Six year trend analysis of plasmodium species by months at Bati district from 2015 to 2020 